\title{
Impact of Preoperative Patient Characteristics and Flow Rate on Failure, Early Complications, and Voiding Dysfunction After a Transobturator Tape Procedure: A Multicentre Study
}

\author{
Andrea Cocci ${ }^{1}$, Giovanni E. Cacciamani2 ${ }^{2,3}$, Giorgio Ivan Russo ${ }^{4}$, Maria Angela Cerruto ${ }^{2}$, Martina Milanesi ${ }^{1}$, Luis G. Medina ${ }^{3}$, \\ Sebastiano Cimino ${ }^{4}$, Walter Artibani², Giuseppe Morgia ${ }^{4}$, Marco Carini ${ }^{1}$, Vincenzo Li Marzi ${ }^{1}$ \\ ${ }^{1}$ Department of Urology, University of Florence, Florence, Italy \\ ${ }^{2}$ Department of Urology, Polo Chirurgico "P. Confortini”, Azienda Ospedaliera Universitaria Integrata, Verona, Italy \\ ${ }^{3}$ Urology Institute, University of Southern California, Los Angeles, CA, USA \\ ${ }^{4}$ Department of Urology, University of Catania, Catania, Italy
}

Purpose: To evaluate the impact of preoperative patient characteristics and flow rate on failure, early postoperative complications, and voiding in patients who underwent transvaginal tension-free vaginal tape-obturator (TVT-O) treatment for uncomplicated stress urinary incontinence (SUI).

Methods: We retrospectively reviewed patients who underwent TVT-O for SUI at 3 Italian centres. The exclusion criteria were predominant voiding and storage symptoms suggestive of detrusor overactivity, the presence of grade $>1$ urogenital prolapse, previous pelvic radiotherapy or other clinical contraindications for surgical procedures, neurogenic bladder dysfunction, and collagen diseases. Multivariate logistic regression models were constructed to identify predictors of early voiding dysfunction after TVT-O.

Results: A total of 219 patients underwent TVT-O between January 2010 and December 2015. All patients received follow-up at 3,6, and 12 months, and underwent a stress test, uroflowmetry, and bladder ultrasound to evaluate the postvoid residual volume. They also responded to the Urogenital Distress Inventory (UDI-6) questionnaire. The rates of persistent incontinence after TVT-O, postoperative complications, and satisfaction were 16.4\% (36 of 219), 24.2\% (53 of 219), and 86.3\% (189 of 219), respectively. Nineteen patients (9.5\%) experienced early voiding dysfunction. Based on an analysis of baseline characteristics, we determined that a cutoff value of 9.0 on the UDI-6 predicted postoperative SUI with $62 \%$ specificity, $72 \%$ sensitivity, and $66 \%$ accuracy. In the multivariate logistic regression analysis, a preoperative UDI- $6 \geq 9.0$ was an independent predictor of postoperative SUI. The predictors of complications were menopause $(\mathrm{P}=0.04)$ and the preoperative UDI- 6 score $(\mathrm{P}=0.01)$. Conclusions: Menopause and UDI-6 scores could be prognostic factors for persistent SUI after TVT-O. Well-designed prospective studies with a suitable number of patients are needed to corroborate our findings.

Keywords: Urinary Incontinence; Uretrhal Sling; Urinary Incontinence, Stress; Tension-Free Vaginal Tape; Urodynamics

- Research Ethics: This study was approved by Institutional Review Board of the participating Institutions (90/2015). A written informed consent was obtained from all subjects.

- Conflict of Interest: No potential conflict of interest relevant to this article was reported.

Corresponding author: Giovanni E. Cacciamani

(iD) https://orcid.org/0000-0002-8892-5539

Department of Urology, Polo Chirurgico "P. Confortini”, Azienda Ospedaliera

Universitaria Integrata, Padiglione 15, Piazzale Aristide Stefani, 1, 37126 Verona, Italy

E-mail: giovanni.cacciamani@gmail.com / Tel: +1-6268402501 / Fax: +1-3232258064

Submitted: May 18, 2017 / Accepted after revision: October 22, 2017 


\section{INTRODUCTION}

Stress urinary incontinence (SUI) is a debilitating condition with a negative impact on well-being due to sexual dysfunction, physical morbidity, and loss of independence, work, and social life. The diagnostic evaluation is based on a careful clinical history, voiding diaries, pad testing, and urodynamic studies [1].

Midurethral slings (MUS) represent the gold standard for the treatment of uncomplicated female SUI [2-4]. The transobturator and retropubic approaches were found to be equally effective for the treatment of SUI [5]. Although the transient voiding dysfunction risk seems to be equivalent between those 2 approaches, the long-term voiding dysfunction risk is lower in patients who undergo transobturator tape (TOT) treatment $[6,7]$.

Voiding dysfunction following MUS has been reported in between $1.6 \%$ and $39 \%$ of cases [8,9], and its management includes long-term intermittent self-catheterization, indwelling bladder catheter placement, and tape mobilization and division; these treatment strategies have important impacts on patients' satisfaction.

Age, severe preoperative urge urinary incontinence, and surgical complications are risk factors for long-term sling failure [10].

Preoperative urodynamic studies have a significant impact on the clinical diagnosis and the likelihood of additional postoperative treatment [8], and it is mandatory to distinguish between complicated and uncomplicated cases of incontinence [11].

Controversy exists regarding the preoperative risk factors for postoperative voiding dysfunction, and the impact of urodynamic factors is still debated $[9,10,12-15]$. As the peak urinary flow rate is an independent predictive factor for urinary retention after tension-free vaginal tape procedures [13], patients with a low preoperative flow rate can safely receive tension-free vaginal tape-obturator (TVT-O) treatment [16].

Furthermore, conflicting results were reported regarding predictors of sling failure [17-21], and sparse data exist on preoperative risk factors of persistent SUI after TOT [8].

The aim of this study was to evaluate the impact of preoperative patient characteristics and flow rate on the failure rate, early postoperative complications, and voiding in patients who underwent TVT-O for uncomplicated SUI.

\section{MATERIALS AND METHODS}

\section{Patient Selection}

We retrospectively reviewed consecutive patients who underwent a TVT-O procedure for uncomplicated SUI at 3 Italian centres (Florence, Verona, and Catania) between January 2010 and December 2015.

The exclusion criteria were predominant voiding and storage symptoms suggestive of detrusor overactivity, based on an analysis of a bladder diary; the presence of grade $>1$ urogenital prolapse (according to the Baden and Walker classification [22]) beyond the hymen or symptomatic prolapse; previous pelvic radiotherapy or other clinical contraindications for surgical procedures; neurogenic bladder dysfunction; and collagen diseases. After receiving instructions and providing written informed consent, all patients underwent a TVT-O procedure.

\section{Patient Evaluation}

Before surgery, all patients underwent a comprehensive assessment including a clinical history (especially for pelvic reconstructive procedures or hysterectomy), a physical examination, pad usage analysis, and uroflowmetry (UFM) according to good urodynamic practices [21]. The Urogenital Distress Inventory (UDI-6), the International Consultation on Incontinence Questionnaire Urinary Incontinence form, a bladder diary, a visual analogue scale, demographic information, medical history, and symptoms of lower urinary tract and pelvic floor dysfunction were assessed before and after MUS surgery. Conservative measures, such as bladder retraining and/or pelvic floor physiotherapy, had been previously tried in all patients, but did not succeed.

\section{Uroflowmetry}

Noninstrumented UFM was performed before the procedure. All patients voided, with a comfortably full bladder, in sitting position into a gravimetric uroflowmeter (Danflow 1100, SynMed Medicinteknik AB, Silkeborg, Denmark). According to good urodynamic practices [21], peak flow rate (PFR), voided volume, and postvoid residual (PVR) volume were recorded.

\section{Surgical Procedure}

Surgery was performed using a TVT-O sling. All patients received broad-spectrum intravenous antibiotic prophylaxis 1 hour before surgery. The operations were performed as previously described $[23,24]$. All procedures were performed under 
local analgesia with light sedation, and a cough stress test was performed intraoperatively to avoid postoperative voiding difficulties.

Cystoscopy was performed in the operating room if visceral lesions were suspected, or during follow-up if the patient presented with postoperative moderate or severely irritative urinary symptoms or recurrent urinary tract infections.

The MUS was adjusted using the cough stress test with an intravesical volume of $300 \mathrm{~mL}$ to prevent urinary leakage and to avoid overtension. Patients were discharged after 2 spontaneous micturition episodes with a PVR $<100 \mathrm{~mL}$. Patients were admitted overnight and discharged with 24 hours of oral antibiotics.

\section{Follow-up After Surgical Procedure}

All patients received follow-up at 3, 6, and 12 months and underwent a stress test, UFM, and bladder ultrasound to evaluate the PVR volume. They also responded to the UDI-6 questionnaire. The patients were considered cured when there was no subjective or objective evidence of SUI. We defined successful SUI treatment as the loss of $<200 \mathrm{~mL}$ of urine or the use of one pad per day, in addition to a negative stress test [20,21]. Early voiding dysfunction was considered to be present when the patient required catheterisation within 48 hours of the procedure [15]. The procedure was considered a failure when the cure criteria were not achieved. The presence of complications, according to the Clavien-Dindo classification [25], and the reoperation rates were evaluated over the course of follow-up as secondary endpoints. Patient satisfaction after treatment was evaluated according to the Patients' Global Impression of Change scale [26].

\section{Statistical Analysis}

Continuous variables are presented as median (interquartile range), and differences between groups were tested by the Student independent $\mathrm{t}$-test or the Mann-Whitney U-test depending on whether their distribution was normal, as tested by the Kolmogorov-Smirnov test.

Multivariate logistic regression models were constructed to identify predictive factors of early voiding dysfunction by including all the collected variables. One thousand bootstrap resamples were used for all accuracy estimates and to reduce the overfit bias. Area under the curve values were also calculated to identify the UDI- 6 cutoff score most suitable for predicting postoperative SUI.
All tests were conducted using IBM SPSS Statistics ver. 19.0 (IBM Co., Armonk, NY, USA). For all statistical comparisons, $\mathrm{P}$-values $<0.05$ were considered to indicate statistical significance.

\section{RESULTS}

A total of 219 patients underwent TVT-O between January 2010 and December 2015. Their baseline characteristics are presented in Table 1. All patients completed follow-up as scheduled, at 3, 6, and 12 months. Their mean age was 59 years, with a median body mass index (BMI) of $27 \mathrm{~kg} / \mathrm{m}^{2} ; 63.9 \%$ of the patients were in menopause. No patients underwent hormone replacement therapy. Table 2 shows the characteristics of the patients according to preoperative PFR.

Diabetes and hypertension were present in $7.7 \%$ and $27.3 \%$ of the cases, respectively. We observed significant changes in the mean PFR $(24.95 \mathrm{~mL} / \mathrm{sec}$ vs. $30.34 \mathrm{~mL} / \mathrm{sec}, \mathrm{P}<0.05)$, mean PVR $(40.85 \mathrm{~mL}$ vs. $7.37 \mathrm{~mL}, \mathrm{P}<0.01)$, and mean UDI-6 score (9.47 vs. $1.36, \mathrm{P}<0.01$ ) after surgery.

Incontinence persisted after surgery in $16.4 \%$ (36 of 219) of the participants, while the satisfaction rate was $86.3 \%$ (189 of 219). The postoperative complication rate was $24.2 \%$ (53 of 219), including 41 cases of Clavien-Dindo classification grade I complications (18.7\%) and 12 cases of Clavien-Dindo classifi-

Table 1. Baseline characteristics of patients $(n=219)$

\begin{tabular}{lc}
\hline Characteristic & Value \\
\hline Age $(\mathrm{yr})$ & $59(50-67)$ \\
Body mass index $\left(\mathrm{kg} / \mathrm{m}^{2}\right)$ & $27(24-29)$ \\
Number of childbirth & $2(1-2)$ \\
Pad/day & $3(2-4)$ \\
Peak flow rate $(\mathrm{mL} / \mathrm{sec})$ & $23.25(18.15-31.37)$ \\
Postvoid residual $(\mathrm{mL})$ & $40.85(37.85-45.22)$ \\
UDI-6 & $10(6-12)$ \\
Menopause & $140(63.9)$ \\
Diabetes & $17(7.8)$ \\
Hypertension & $60(27.4)$ \\
Type of childbirth & $145(66.2)$ \\
Normal & $20(9.1)$ \\
Episiotomy & $21(9.6)$ \\
Dystocic & $33(15.1)$ \\
Laceration &
\end{tabular}

Values are presented as median (interquartile range) or number (\%). UDI-6, Urogenital Distress Inventory. 
Table 2. Characteristics of patients according to preoperative peak flow rate

\begin{tabular}{|c|c|c|c|}
\hline \multirow{2}{*}{ Characteristic } & \multicolumn{2}{|c|}{$\operatorname{Qmax}(\mathrm{mL} / \mathrm{sec})$} & \multirow{2}{*}{ P-value } \\
\hline & $<15(\mathrm{n}=21)$ & $\geq 15(\mathrm{n}=180)$ & \\
\hline Age (yr) & $59.87(53.83-72.76)$ & $58.0(50.48-65.93)$ & 0.58 \\
\hline Body mass index $\left(\mathrm{kg} / \mathrm{m}^{2}\right)$ & $27.34(24.57-30.31)$ & $26.56(23.88-29.38)$ & 0.43 \\
\hline Number of childbirth & $2(1-2)$ & $2(1-2)$ & 0.47 \\
\hline $\mathrm{Pad} /$ day & $3(2-4)$ & $3(2-4)$ & 0.42 \\
\hline Preoperative UDI-6 & $9.47(7.5-13.0)$ & $9.47(9.0-11.0)$ & 0.43 \\
\hline Preoperative voided volume & $370.0(318.5-408.52)$ & - & \\
\hline Menopause & $15(71.4)$ & $125(69.4)$ & 0.85 \\
\hline $\begin{array}{l}\text { Type of childbirth } \\
\text { Normal } \\
\text { Episiotomy } \\
\text { Dystocic } \\
\text { Laceration }\end{array}$ & $\begin{array}{c}12(57.1) \\
1(4.8) \\
5(23.8) \\
3(14.3)\end{array}$ & $\begin{array}{c}115(63.9) \\
19(10.6) \\
16(8.9) \\
30(16.7)\end{array}$ & 0.18 \\
\hline Postoperative PFR & $30.34(25.50-30.34)$ & $30.34(26.62-30.34)$ & 0.68 \\
\hline Postoperative UDI6 & $1.36(0-1.68)$ & $1.36(0-1.36)$ & 0.89 \\
\hline Postoperative voided volume & $329.16(319.20-335.6)$ & $329.16(307.50-339.16)$ & 0.35 \\
\hline Postoperative PFR-preoperative PFR & $17.5(15.17-22.09)$ & $4.74(-4.17$ to 9.46$)$ & $<0.01$ \\
\hline Postoperative voided volume-preoperative voided volume & $-79.35(-101.02$ to -13.83$)$ & $-79.35(-128.14$ to 59.62$)$ & 0.36 \\
\hline
\end{tabular}

Values are presented as median (interquartile range) or number (\%).

Qmax, maximum flow rate; UDI-6, Urogenital Distress Inventory; PFR, peak flow rate.

Table 3. Multivariate logistic regression of predictive factors of failure of TVT-O

\begin{tabular}{lcc}
\hline Variable & OR $(95 \% \mathrm{CI})$ & P-value \\
\hline Age $(\mathrm{yr})$ & $1.02(0.94-1.10)$ & 0.60 \\
Body mass index $\left(\mathrm{kg} / \mathrm{m}^{2}\right)$ & $1.17(0.97-1.40)$ & 0.09 \\
Number of childbirth & $0.62(0.32-1.18)$ & 0.15 \\
Pad/day & $1.12(0.95-1.32)$ & 0.18 \\
Peak flow rate $(\mathrm{mL} / \mathrm{sec})$ & $0.97(0.90-1.04)$ & 0.43 \\
Postvoid residual $(\mathrm{mL})$ & $1.00(0.99-1.01)$ & 0.43 \\
UDI-6 & $1.24(1.04-1.50)$ & 0.02 \\
Menopause & $6.19(0.68-56.45)$ & 0.03 \\
Type of childbirth & $1.64(0.11-23.22)$ & 0.72 \\
\hline
\end{tabular}

TVT-O, tension-free vaginal tape-obturator; OR, odds ratio; CI, confidence interval; UDI-6, Urogenital Distress Inventory.

cation grade II complications (5.5\%). No major complications (Clavien-Dindo classification grade $\geq$ III) were observed.

In the multivariate logistic regression analysis, the preoperative UDI-6 score (odds ratio [OR], 1.21; 95\% confidence interval $[\mathrm{CI}], 1.04-1.50 ; \mathrm{P}=0.02)$ and menopause $(\mathrm{OR}, 6.19 ; 95 \%$ CI, $0.68-56.45 ; \mathrm{P}=0.03$ ) were independent predictors of failure after a TVT-O procedure (Table 3 ).
Based on a receiver operating characteristics analysis, we determined that a cutoff value of 9.0 on the UDI- 6 scale predicted postoperative SUI with $62 \%$ specificity, $72 \%$ sensitivity, and $66 \%$ accuracy. In the multivariate logistic regression analysis, a preoperative UDI-6 score $\geq 9.0$ (OR, 2.81; 95\% CI, 0.96-8.22; $\mathrm{P}=0.04)$ was an independent predictor of postoperative SUI. The only predictors of complications were menopause (OR, 6.44; 95\% CI, 1.26-32.94; $\mathrm{P}=0.04)$ and the preoperative UDI-6 score (OR, 1.23; 95\% CI, 1.05-1.34; $\mathrm{P}=0.01)$. After surgery, 19 patients (9.5\%) experienced early voiding dysfunction. In the multivariate logistic regression analysis (adjusted for age, BMI, number of children, and the UDI-6 score), the preoperative PFR (OR, 0.98; $\mathrm{P}=0.62)$ and preoperative PVR (OR, 0.99; $\mathrm{P}=0.25$ ) were not associated with early voiding dysfunction.

\section{DISCUSSION}

MUS represent the gold standard treatment for SUI, with high rates of recovery of continence. Since transvaginal tape was introduced in 1996, this procedure has become one of the most commonly used SUI treatments [21]. The TOT procedure appears to be associated with a lower incidence of postoperative 
voiding dysfunction [27]. However, some patients may present voiding dysfunction after surgery. In fact, no standard definition exists of postoperative voiding dysfunction after anti-incontinence surgery.

The International Urogynecological Association/International Continence Society joint report on the terminology for female pelvic floor dysfunction defines voiding dysfunction as follows: "Voiding dysfunction, a diagnosis by symptoms and urodynamic investigations, is defined as abnormally slow and/or incomplete micturition. Hesitancy is a complaint of a delay in initiating micturition. Slow stream is a complaint of urinary stream perceived as slower compared to previous performance or in comparison with others. Intermittency is a complaint of urine flow that stops and starts on one or more occasions during voiding. Feeling of incomplete (bladder) emptying is a complaint that the bladder does not feel empty after passing urine. PVR (urine volume) quote upper limits of normal of 50 or $100 \mathrm{~mL}$ ' [28].

The treatment of voiding dysfunction is still controversial and depends from the timing of onset. Several options can be used, including short- (up to 48 hours) or long-term self-catheterisation, tape mobilisation (2.4\% of cases), or tape loosening to achieve a more desirable tension without interfering with the urinary flow [29].

In our study, we identified early voiding dysfunction in 19 of 219 patients (9.5\%) who underwent TVT-O and required urethral catheterization within $24-48$ hours after Foley catheter removal.

Mutone et al. [15] demonstrated that, in 153 patients who underwent TVT, previous incontinence surgery and previous prolapse $(\mathrm{P}=0.08$ and $\mathrm{P}=0.06)$ were associated with voiding dysfunction.

Lucena et al. [13] reviewed 100 patients who underwent a retropubic MUS procedure. The univariate analysis demonstrated that an abnormal PFR for voiding was associated with an increased risk of voiding dysfunction $(\mathrm{P}=0.046)$ and that women with a larger bladder capacity $(490 \mathrm{~mL}$ vs. $457 \mathrm{~mL}$, $\mathrm{P}=0.04$ ) were slightly protected.

Preoperative urodynamic assessments aim to confirm the diagnosis (in case of doubt), to demonstrate the mechanism(s), and to identify factors that may affect treatment outcomes. However, whether urodynamic assessments improve long-term outcomes following surgery remains controversial, and there is a lack of high-level evidence to support the assertion that urodynamic assessments can predict the complications of surgery [30].

Some studies have demonstrated that preoperative urody- namic findings, such as high preoperative PVR, low preoperative PFR, and low detrusor pressure during a pressure-flow study, might predict postoperative voiding dysfunction after anti-incontinence surgery [31-33].

Nevertheless, other studies have failed to demonstrate urodynamic predictors of post-MUS voiding dysfunction. Chang et al. [34] postoperatively evaluated 449 patients who underwent TOT. Preoperative urodynamic parameters did not demonstrate reproducible predictors of voiding dysfunction.

In our study, the preoperative flow rate was not shown to be a potential risk factor for the occurrence of early voiding dysfunction after a TVT-O procedure. The postoperative incontinence rate was $16.4 \%$, the complication rate was $24.2 \%$, and the satisfaction rate was $86.3 \%$.

Serati et al. [16], in a prospective, multicentre, observational study of 191 women presenting with urodynamically proven pure SUI treated by TVT-O, documented that failure of a previous incontinence treatment procedure was the only independent predictor of subjective recurrence of SUI (hazard ratio [HR], 4.4; $\mathrm{P}=0.009$ ) or objective recurrence (HR, 3.7; $\mathrm{P}=0.02)$.

In our study, menopause and the UDI- 6 score were the only preoperative risk factors for early TVT-O failure and early complications. An interpretation of these findings could be related to the sensitivity of the lower urinary tract to estrogens due to its shared common embryological origin with the female genital tract [35]. Substantial hormonal changes happen at menopause, with impacts on all oestrogen-sensitive tissues. In particular, oestrogens target the functional layers of the urethra (epithelium, vasculature, connective tissue, and muscle) which are fundamental for maintaining continence.

However, some limitations should be addressed. First, the retrospective nature of the study should be considered. Moreover, we did not collect more details about diabetes, such as glycated haemoglobin levels, which may be risk factors for incontinence.

In conclusion, women suffering from uncomplicated SUI with a low preoperative flow rate can safely undergo TVT-O. The short-term treatment success rate was found to be high. Menopause and the UDI-6 score may be prognostic factors for persistent SUI after TVT-O. Well-designed prospective studies with a suitable number of patients are needed to corroborate our findings. 


\section{REFERENCES}

1. Urinary incontinence [Internet]. Arnhem (the Netherlands): European Association of Urology; c2017 [cited 2017 May 20]. Available from: http://uroweb.org/guideline/urinary-incontinence/.

2. Chughtai BI, Elterman DS, Vertosick E, Maschino A, Eastham JA, Sandhu JS. Midurethral sling is the dominant procedure for female stress urinary incontinence: analysis of case logs from certifying American Urologists. Urology 2013;82:1267-71.

3. Cox A, Herschorn S, Lee L. Surgical management of female SUI: is there a gold standard? Nat Rev Urol 2013;10:78-89.

4. Novara G, Artibani W, Barber MD, Chapple CR, Costantini E, Ficarra $\mathrm{V}$, et al. Updated systematic review and meta-analysis of the comparative data on colposuspensions, pubovaginal slings, and midurethral tapes in the surgical treatment of female stress urinary incontinence. Eur Urol 2010;58:218-38.

5. Artibani W, Cerruto MA. Dysfunctional voiding. Curr Opin Urol 2014;24:330-5.

6. Novara G, Galfano A, Boscolo-Berto R, Secco S, Cavalleri S, Ficarra $\mathrm{V}$, et al. Complication rates of tension-free midurethral slings in the treatment of female stress urinary incontinence: a systematic review and meta-analysis of randomized controlled trials comparing tension-free midurethral tapes to other surgical procedures and different devices. Eur Urol 2008;53:288-308.

7. Serati M, Topazio L, Bogani G, Costantini E, Pietropaolo A, Palleschi $\mathrm{G}$, et al. Urodynamics useless before surgery for female stress urinary incontinence: Are you sure? Results from a multicenter single nation database. Neurourol Urodyn 2016;35:809-12.

8. Barron KI, Savageau JA, Young SB, Labin LC, Morse AN. Prediction of successful voiding immediately after outpatient mid-urethral sling. Int Urogynecol J Pelvic Floor Dysfunct 2006;17:570-5.

9. Sun X, Yang Q, Sun F, Shi Q. Comparison between the retropubic and transobturator approaches in the treatment of female stress urinary incontinence: a systematic review and meta-analysis of effectiveness and complications. Int Braz J Urol 2015;41:220-9.

10. Klutke C, Siegel S, Carlin B, Paszkiewicz E, Kirkemo A, Klutke J. Urinary retention after tension-free vaginal tape procedure: incidence and treatment. Urology 2001;58:697-701.

11. Hong B, Park S, Kim HS, Choo MS. Factors predictive of urinary retention after a tension-free vaginal tape procedure for female stress urinary incontinence. J Urol 2003;170:852-6.

12. Cetinel B, Demirkesen O, Onal B, Akkus E, Alan C, Can G. Are there any factors predicting the cure and complication rates of tension-free vaginal tape? Int Urogynecol J Pelvic Floor Dysfunct 2004;15:188-93.
13. Lucena HM, Rai H, Siozos C, Tincello DG, Basak S, Giarenis I. Early postoperative voiding dysfunction after insertion of retropubic midurethral tape. Int Urogynecol J 2016;27:1529-33.

14. Minassian VA, Al-Badr A, Drutz HP, Lovatsis D. Tension-free vaginal tape, Burch, and slings: are there predictors for early postoperative voiding dysfunction? Int Urogynecol J Pelvic Floor Dysfunct 2004;15:183-7.

15. Mutone N, Brizendine E, Hale D. Factors that influence voiding function after the tension-free vaginal tape procedure for stress urinary incontinence. Am J Obstet Gynecol 2003;188:1477-81.

16. Serati M, Bauer R, Cornu JN, Cattoni E, Braga A, Siesto G, et al. TVT-O for the treatment of pure urodynamic stress incontinence: efficacy, adverse effects, and prognostic factors at 5-year follow-up. Eur Urol 2013;63:872-8.

17. Leone Roberti Maggiore U, Finazzi Agrò E, Soligo M, Li Marzi V, Digesu A, Serati M. Long-term outcomes of TOT and TVT procedures for the treatment of female stress urinary incontinence: a systematic review and meta-analysis. Int Urogynecol J 2017;28: 1119-30.

18. Rafii A, Daraï E, Haab F, Samain E, Levardon M, Deval B. Body mass index and outcome of tension-free vaginal tape. Eur Urol 2003;43:288-92.

19. Schäfer W, Abrams P, Liao L, Mattiasson A, Pesce F, Spangberg A, et al. Good urodynamic practices: uroflowmetry, filling cystometry, and pressure-flow studies. Neurourol Urodyn 2002;21:261-74.

20. Serati M, Ghezzi F, Cattoni E, Braga A, Siesto G, Torella M, et al. Tension-free vaginal tape for the treatment of urodynamic stress incontinence: efficacy and adverse effects at 10-year follow-up. Eur Urol 2012;61:939-46.

21. Ulmsten U, Henriksson L, Johnson P, Varhos G. An ambulatory surgical procedure under local anesthesia for treatment of female urinary incontinence. Int Urogynecol J Pelvic Floor Dysfunct 1996;7:81-5.

22. Baden WF, Walker TA. Genesis of the vaginal profile: a correlated classification of vaginal relaxation. Clin Obstet Gynecol 1972;15: 1048-54.

23. de Leval J. Novel surgical technique for the treatment of female stress urinary incontinence: transobturator vaginal tape inside-out. Eur Urol 2003;44:724-30.

24. Delorme E. Transobturator urethral suspension: mini-invasive procedure in the treatment of stress urinary incontinence in women. Prog Urol 2001;11:1306-13.

25. Dindo D, Demartines N, Clavien PA. Classification of surgical complications: a new proposal with evaluation in a cohort of 6336 patients and results of a survey. Ann Surg 2004;240:205-13. 
26. Hurst $\mathrm{H}$, Bolton J. Assessing the clinical significance of change scores recorded on subjective outcome measures. J Manipulative Physiol Ther 2004;27:26-35.

27. Morey AF, Medendorp AR, Noller MW, Mora RV, Shandera KC, Foley JP, et al. Transobturator versus transabdominal mid urethral slings: a multi-institutional comparison of obstructive voiding complications. J Urol 2006;175(3 Pt 1):1014-7.

28. Haylen BT, Freeman RM, Swift SE, Cosson M, Davila GW, Deprest J, et al. An International Urogynecological Association (IUGA)/International Continence Society (ICS) joint terminology and classification of the complications related directly to the insertion of prostheses (meshes, implants, tapes) and grafts in female pelvic floor surgery. Neurourol Urodyn 2011;30:2-12.

29. Glavind K, Shim S. Incidence and treatment of postoperative voiding dysfunction after the tension-free vaginal tape procedure. Int Urogynecol J 2015;26:1657-60.

30. Osman NI, Marzi VL, Cornu JN, Drake MJ. Evaluation and classi- fication of stress urinary incontinence: current concepts and future directions. Eur Urol Focus 2016;2:238-44.

31. Kleeman S, Goldwasser S, Vassallo B, Karram M. Predicting postoperative voiding efficiency after operation for incontinence and prolapse. Am J Obstet Gynecol 2002;187:49-52.

32. Miller EA, Amundsen CL, Toh KL, Flynn BJ, Webster GD. Preoperative urodynamic evaluation may predict voiding dysfunction in women undergoing pubovaginal sling. J Urol 2003;169:2234-7.

33. Asimakopoulos AD, Cerruto MA, Del Popolo G, La Martina M, Artibani W, Carone R, et al. An overview on mixed action drugs for the treatment of overactive bladder and detrusor overactivity. Urol Int 2012;89:259-69.

34. Ahn C, Bae J, Lee KS, Lee HW. Analysis of voiding dysfunction after transobturator tape procedure for stress urinary incontinence. Korean J Urol 2015;56:823-30.

35. Iosif CS, Batra S, Ek A, Astedt B. Estrogen receptors in the human female lower uninary tract. Am J Obstet Gynecol 1981;141:817-20. 